EPJ Web of Conferences 45, 01020 (2013)

DOI: $10.1051 /$ epjconf/20134501020

(C) Owned by the authors, published by EDP Sciences, 2013

\title{
Pool boiling on rectangular fins with tunnel-pore structure
}

\author{
R. Pastuszko
}

Kielce University of Technology, Department of Mechanics, Al. Tysiaclecia P.P.7, 25-314 Kielce, Poland

\begin{abstract}
Complex experimental investigations were conducted in the area of pool boiling heat transfer on extended surfaces with internal tunnels limited by perforated foil. The experiments were carried out for water and R-123 at atmospheric pressure. The tunnel surfaces were fabricated from $0.05-0.1 \mathrm{~mm}$ thick perforated copper foil (pore diameters: $0.3,0.4,0.5 \mathrm{~mm}$ ) sintered with mini-fins formed by 5 and $10 \mathrm{~mm}$ high rectangular fins and horizontal inter-fin surface. The effect of the main fin height, pore diameters and tunnel pitch on nucleate pool boiling was examined. Substantial enhancement of heat transfer coefficient was observed for the investigated surfaces. The highest increase in the heat transfer coefficient was obtained for the $10 \mathrm{~mm}$ high fins - about $50 \mathrm{~kW} / \mathrm{m}^{2} \mathrm{~K}$ for water and $15 \mathrm{~kW} / \mathrm{m}^{2} \mathrm{~K}$ for R-123. The investigated surfaces showed boiling heat transfer coefficients similar to those of existing tunnel-pore structures.
\end{abstract}

\section{Nomenclature}

h $\quad$ - height, mm

p - tunnel pitch, mm

$q \quad$ - heat flux, $\mathrm{kW} / \mathrm{m}^{2}$

$s \quad-$ width of space between fins, $\mathrm{mm}$

$T$ - temperature, $\mathrm{K}$

TS - tunnell structure

w - width, mm

Greek symbols

$\alpha \quad$ - heat transfer coefficient, $\mathrm{kW} / \mathrm{m}^{2} \mathrm{~K}$

$\delta$ - fin thickness, $\mathrm{mm}$

$\Delta T$ - wall superheating, $\mathrm{K}$

Subscripts

b - base

p - pore

sat - saturation

tun - tunnel

\section{Introduction}

The trend toward miniaturization of mechanical and electronic equipment components is the driving force behind ever better cooling technologies designed to prevent exceeding maximum allowable operating temperatures. The change of phase that accompanies boiling and condensing processes allows obtaining the highest possible heat flux at a low temperature difference between a heating surface and a working fluid on a small heat-transfer area.

There are a variety of passive and active methods of boiling heat transfer enhancement - this paper focuses on the system of subsurface mini-tunnels restrained by a porous structure in a form of perforated foil (tunnelpore surface).

Tunnel-pore surfaces provide high heat transfer coefficients but the surface manufacturing technology requires joining (typically soldering) the base surface with the upper perforated or porous structure. A variety of models have been developed for boiling on such surfaces, mainly for suction-evaporation type of boiling, due to relatively high accuracy of manufacture and repeatability of dimensions.

Ma et al. [1] analysed boiling heat transfer for water and methanol on surfaces with parallel grooves, covered with brass mesh welded to a plate with holes (pores). The best results were obtained for the surface with trapezoid fins where the lowest superheats at small heat fluxes were observed. The optimum pore diameters were found to be $160 \mu \mathrm{m}$ for boiling water and $160-$ $220 \mu \mathrm{m}$ for methanol. Nakayama et al. [2] used tunnels of rectangular cross-sections with triangular pores. They found that the surface pores of about $0.1 \mathrm{~mm}$ in size (equivalent to inscribed circle diameter) gave the best heat transfer enhancement for the boiling of water, R-11 and liquid nitrogen. Arshad and Thome [3] investigated flat surfaces similar to those of Nakayama et al. but for various tunnel cross-sections: rectangular, triangular and circular. The optimum heat transfer enhancement was provided by the surface with pores of $0.25 \mathrm{~mm}$ in diameter. The experiments described by Chien and Webb [4,5] were carried out with freon R-11 and R123. The best results were obtained for fins of $1.5 \mathrm{~mm}$ pitch, $0.7-1.0 \mathrm{~mm}$ height and foil holes diameters of 
0.23 mm. Pastuszko [6] presented complex experimental investigations of boiling heat transfer from tunnel structure (TS) formed with $5 \mathrm{~mm}$ high fins. For water and ethanol, the highest increase in the heat transfer coefficient for TS with a pitch of $2 \mathrm{~mm}$ was obtained for the smallest of the investigated holes, i.e. $0.3 \mathrm{~mm}$. The reverse was true for R-123: the best surfaces were those with perforated foil and hole diameters of 0.4 and $0.5 \mathrm{~mm}$.

\section{Experimental research}

\subsection{Tunnel structure surfaces}

Samples with tunnel structure (TS) formed a square of $27 \mathrm{~mm}$ side length. They had three main fins with additional surface modification. Grooves were cut on fins lateral (vertical) surface and horizontal inter-fin spaces, perforated copper foil was sintered to the machined surfaces (figure 1). The constant parameters of the samples were as follows (figure 1, table 1):

- fin number: 3,

- fin height: 5 i $10 \mathrm{~mm}\left(h_{\mathrm{f}}\right)$,

- fin thickness: $5 \mathrm{~mm}\left(\delta_{\mathrm{f}}\right)$,

- inter-fin space width: $5 \mathrm{~mm}(\mathrm{~s})$,

- tunnel height: $1.6 \mathrm{~mm}\left(h_{\text {tun }}\right)$,

- tunnel width: $1.3 \mathrm{~mm}\left(w_{\text {tun }}\right)$.

Table 1. Samples codes and specifications.

\begin{tabular}{ccc}
\hline \multicolumn{3}{c}{ Low fins $\left(\boldsymbol{h}_{\mathbf{f}}=\mathbf{5} \mathbf{~ m m}\right)$} \\
\hline Code & $d_{\mathrm{p}}, \mathrm{mm}$ & $p_{\text {tun }}, \mathrm{mm}$ \\
\hline TS-5-2.00-0.3 & 0.3 & 2.00 \\
\hline TS-5-2.00-0.4 & 0.4 & 2.00 \\
\hline TS-5-2.00-0.5 & 0.5 & 2.00 \\
\hline TS-5-2.25-0.3 & 0.3 & 2.25 \\
\hline TS-5-2.25-0.4 & 0.4 & 2.25 \\
\hline TS-5-2.25-0.5 & 0.5 & 2.25 \\
\hline TS-5-2.50-0.3 & 0.3 & 2.50 \\
\hline TS-5-2.50-0.4 & 0.4 & 2.50 \\
\hline TS-5-2.50-0.5 & 0.5 & 2.50 \\
\hline High fins $\left(\boldsymbol{h}_{\mathbf{f}}=\mathbf{1 0} \mathbf{~ m m}\right)$ \\
\hline Code & $d_{\mathrm{p}}, \mathrm{mm}$ & $p_{\text {tun }}, \mathrm{mm}$ \\
\hline TS-10-2.00-0.3 & 0.3 & 2.00 \\
\hline TS-10-2.00-0.4 & 0.4 & 2.00 \\
\hline TS-10-2.00-0.5 & 0.5 & 2.00 \\
\hline TS-10-2.25-0.3 & 0.3 & 2.25 \\
\hline TS-10-2.25-0.4 & 0.4 & 2.25 \\
\hline TS-10-2.25-0.5 & 0.5 & 2.25 \\
\hline TS-10-2.50-0.3 & 0.3 & 2.50 \\
\hline TS-10-2.50-0.4 & 0.4 & 2.50 \\
\hline TS-10-2.50-0.5 & 0.5 & 2.50 \\
\hline
\end{tabular}
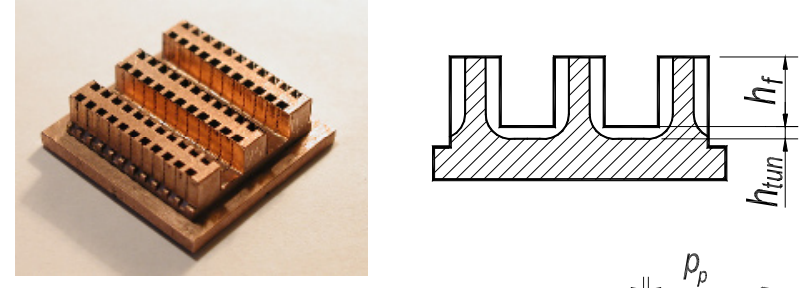

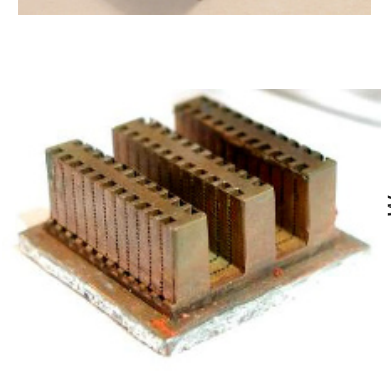

a)



b)
Fig. 1. Investigated TS surfaces: a) views of the samples with 5 and $10 \mathrm{~mm}$ high fins, b) cross sections.

\subsection{Experimental set-up}

The diagram of the measurement stand for the determination of boiling curves is presented in figure 2 .

The main stand module consisted of a cylindrical glass vessel (6) filled with boiling liquid (5), placed over the investigated sample (4). The sample was soldered to a cylindrical copper bar (2) with the cartridge heater inside (1). The bar was insulated with air gaps and a layer of ceramic insulation. Seven thermocouples were placed in the liquid, under the sample and in the bar at the depth of 5,17.5 and $30 \mathrm{~mm}$. Instruments used to detect the thermocouple signals provided accuracy of $\pm 0.3 \mathrm{~K}$ (absolute temperature) and $\pm 0.05 \mathrm{~K}$ on differential values.

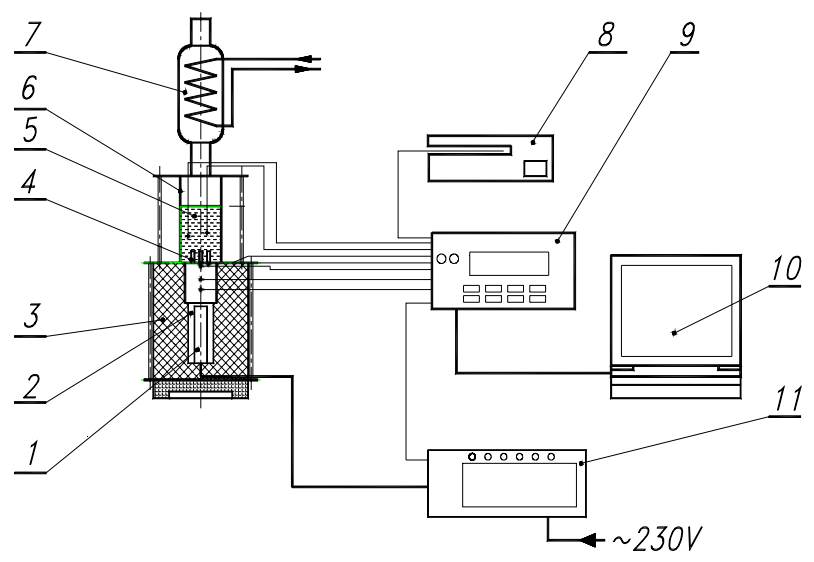

Fig. 2. Schematic diagram of the test system: $1-$ cartridge heater; 2 - copper bar; 3 - Teflon casing; 4 investigated sample; 5 - boiling liquid; 6 - glass vessel; 7 condenser; 8 - dry-well calibrator; 9 - data logger; 10 - PC; 11 - regulated AC power supply. 
The relative error in the determination of the heat flux ranged from $15 \%$ for $q=20 \mathrm{~kW} / \mathrm{m}^{2}$ to $0.6 \%$ for $q=$ $550 \mathrm{~kW} / \mathrm{m}^{2}$. The quoted heat fluxes referred to the fin bases. The base heat transfer coefficient was expressed as:

$$
\alpha=\frac{q}{T_{\mathrm{b}}-T_{\mathrm{sat}}}=\frac{q}{\Delta T}
$$

\section{Results}

\subsection{Water boiling}

Figure 3 shows heat transfer coefficients in relation to heat flux from surfaces with the main fins of 5 and 10 $\mathrm{mm}$ in height. The highest coefficients, about 47.5 $\mathrm{kW} / \mathrm{m}^{2} \mathrm{~K}$, were calculated for surfaces with $10 \mathrm{~mm}$ high fins and tunnels arranged at the widest pitch $(2.5 \mathrm{~mm})$, and pores of the largest diameter $(0.5 \mathrm{~mm})$. In the case of lower fins $(5 \mathrm{~mm})$, the surface that had the highest coefficient (TS-5-2.50-0.3) provided 30\% smaller $\alpha$.

To intensify liquid supply to vertical tunnels where higher fins were used, the pores have to be larger in diameter. Wider pitch reduces the number of tunnels but the walls separating the tunnels are thicker, which results in lower temperature drop along the main fins height and higher superheat at the fin tips, the bubbles departure site. Where fins are $5 \mathrm{~mm}$ high, the pores of the smallest diameters give the best results. The characteristic feature is that the pitch of $2.25 \mathrm{~mm}$ and 0.3 and $0.4 \mathrm{~mm}$ pores at $q>300 \mathrm{~kW} / \mathrm{m}^{2}$ provide almost identical heat transfer coefficients for 5 and $10 \mathrm{~mm}$ high fins.

\subsection{R-123 boiling}

An analysis of R-123 boiling curves (figure 4) also shows the advantage of $10 \mathrm{~mm}$ high main fins - the highest heat transfer coefficients are about $35 \%$ higher that maximum $\alpha$ obtained from the TS surface with 5 $\mathrm{mm}$ fins. Similarly to the case of boiling water, wide pitches in combination with pores of $0.5 \mathrm{~mm}$ in diameter gave the optimal results. Good results were also obtained for surfaces with tunnels arranged with the pitch of $2 \mathrm{~mm}$ and pores of medium diameters $(0.4$ $\mathrm{mm})$.

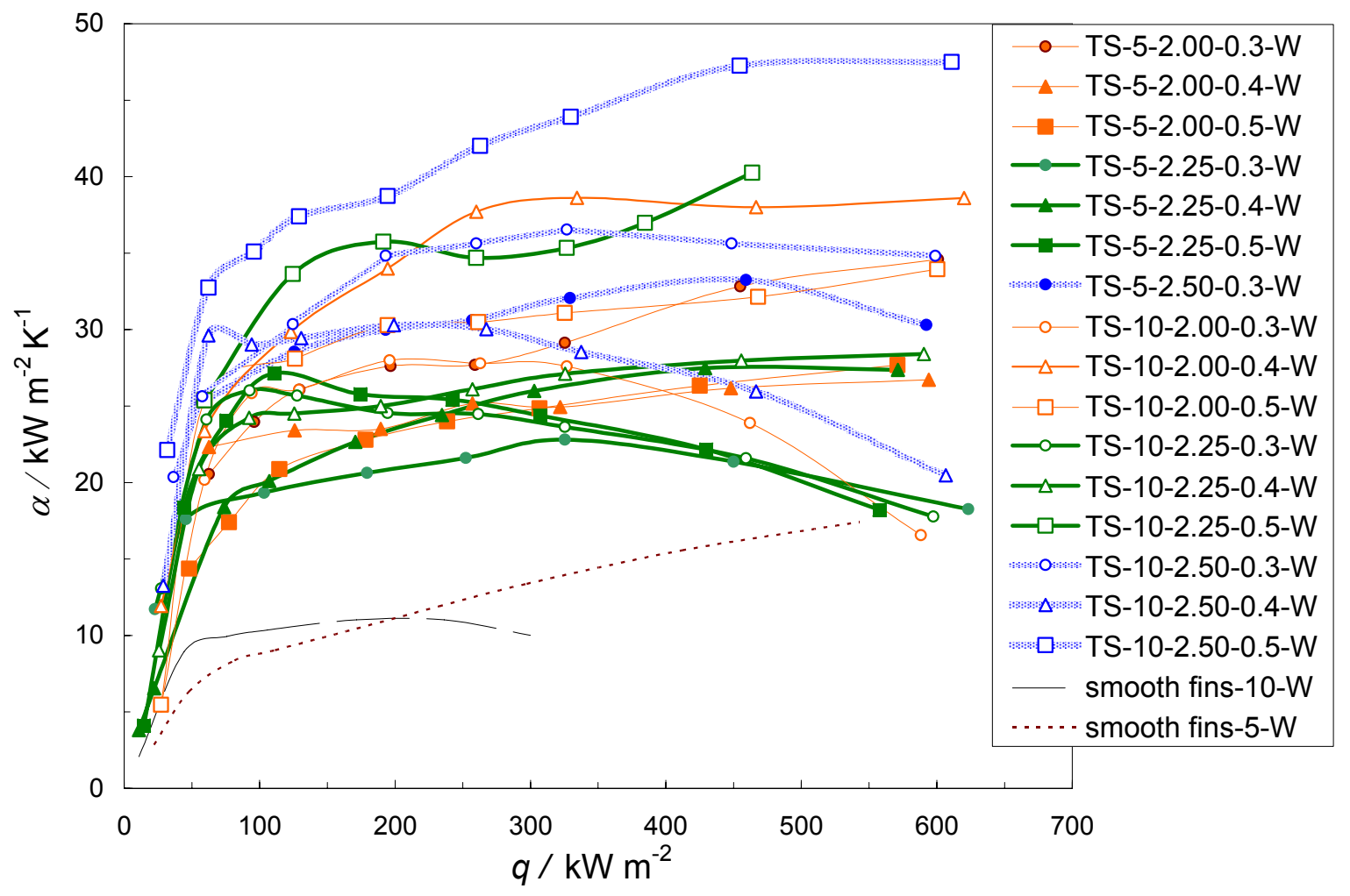

Fig. 3. Surfaces TS - boiling curves for water 


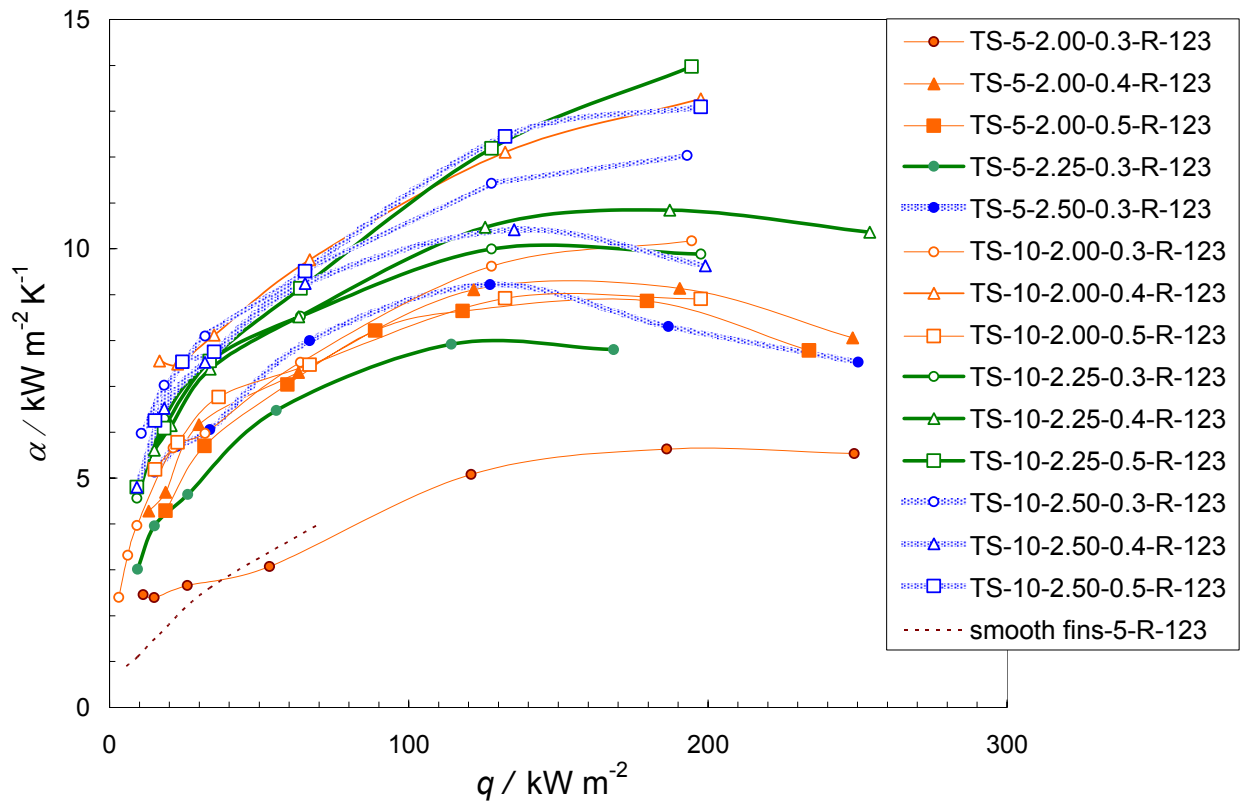

Fig. 4. Surfaces TS - boiling curves for R-123.

\subsection{Simulation examples}

Figures 5 and 6 show examples of boiling curves obtained by changing pore diameters $(0.1-0.7 \mathrm{~mm})$ and tunnel widths $(0.4-1.6 \mathrm{~mm})$.

The simulations were performed on the TS surface model presented in [7]. Decrease in pore diameter causes decrease in their pitch $\left(p_{\mathrm{p}}=2 d_{\mathrm{p}}\right)$, which increases the density of nucleation sites in the horizontal tunnel and makes $q$ higher. But intensive vapor generation stops the liquid inflow into the horizontal and vertical tunnel and the heat fluxes for the smallest pores at $\Delta T>5 \mathrm{~K}$ are lower than those for pores of 0.4 and $0.5 \mathrm{~mm}$ in diameter (figure 7).

The trend presented in figure 5 was confirmed by the results of the experimental investigations of boiling on TS surfaces with $5 \mathrm{~mm}$ high fins (figure 8). The simulation in figure 6 shows that reducing the tunnel width to $0.4 \mathrm{~mm}$ at the superheat of $18 \mathrm{~K}$ ensures obtaining 30\% higher heat fluxes.

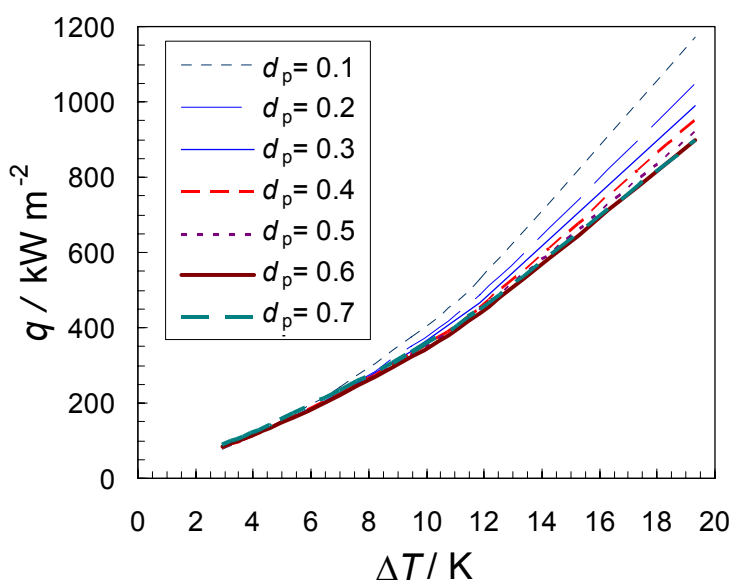

Fig. 5. Simulated boiling curves for different pore diameters at the fixed tunnel pitch $p_{\text {tun }}=2 \mathrm{~mm}$, tunnel width $w_{\text {tun }}=1.3 \mathrm{~mm}$, and fin height $h_{\mathrm{f}}=10 \mathrm{~mm}$.



Fig. 6. Simulated boiling curves for different tunnel widths at the fixed tunnel pitch $p_{\text {tun }}=2 \mathrm{~mm}$, pore diameter $d_{\mathrm{p}}=0.3 \mathrm{~mm}$ and fin height $h_{\mathrm{f}}=10 \mathrm{~mm}$.

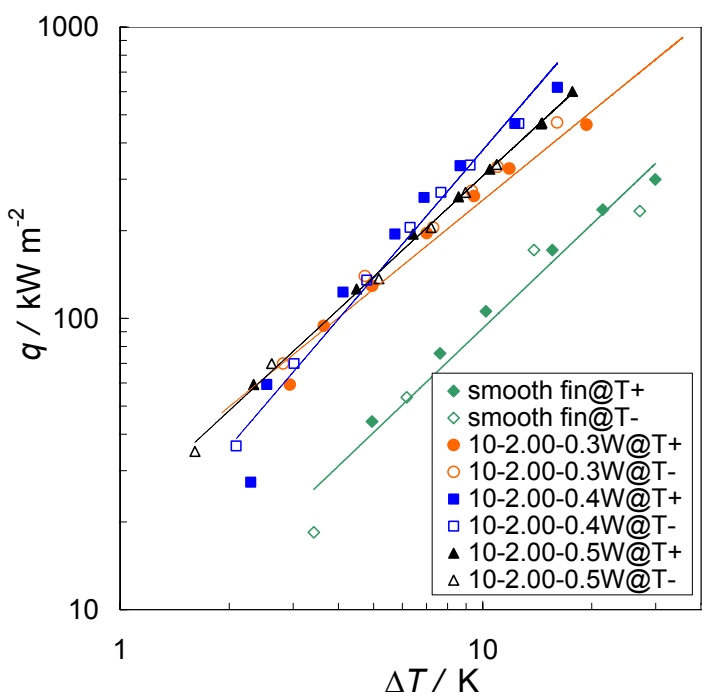

Fig 7. Effect of pore diameter on heat flux for boiling water, fin height $10 \mathrm{~mm}$, tunnel pitch $2 \mathrm{~mm}, \mathrm{~T}+-$ increasing superheat, $\mathrm{T}$ - - decreasing superheat. 




Fig 8. Effect of pore diameter on heat flux for boiling water, fin height $5 \mathrm{~mm}$, tunnel pitch $2 \mathrm{~mm}, \mathrm{~T}+-$ increasing superheat, T- decreasing superheat.

\section{Conclusions}

Based on the experimental investigation results for the presented ranges of the particular surfaces geometrical parameter changes, the following conclusions can be drawn:

- The highest heat transfer coefficients for boiling of water and R-123 were calculated from tunnel structures arranged with the pitch of $2.5 \mathrm{~mm}$ in 10 $\mathrm{mm}$ high fins, limited with the foil with pores of 0.5 $\mathrm{mm}$ in diameter.

- The heat transfer coefficients obtained during the investigations were $3-4$ times higher than those for the smooth fins in the case of water.

- The main fins of $5 \mathrm{~mm}$ in height reduced $\alpha$ by at least $30 \%$ in relation to $10 \mathrm{~mm}$ high fins.

- The simulations presented here indicate the direction of TS surfaces modification for further boiling heat transfer intensification: reducing the tunnel widths up to about $0.4 \mathrm{~mm}$ and reducing the pore diameters.

\section{References}

1. T. Ma, X. Liu, J. Wu, H. Li, proc. 8th Int. Heat Transfer Conf., San Francisco, 2013-2018 (1986)

2. W. Nakayama, T. Daikoku, H. Kuwahara, T. Nakajima, Journal of Heat Transfer 102, 445-450 (1980)

3. J. Arshad, J.R. Thome, proc. ASME-JSME Thermal Eng. Joint Conf. 1, 191-197 (1983)

4. L.-H. Chien, R.L. Webb, ASME-HDT 326, 129-136 (1996)

5. L.-H. Chien, R.L. Webb, ASME-HDT 326, 137-143, (1996)

6. R. Pastuszko, Exp. Thermal Fluid Science 32, 1564 1577 (2008)
7. R. Pastuszko, M.E. Poniewski, Int. J. Thermal Sciences 47, 1169-1183 (2008) 